\title{
Induction of feline immunodeficiency virus specific antibodies in cats with an attenuated Salmonella strain expressing the Gag protein
}

\author{
Edwin J. Tijhaar*\&, Kees H.J. Siebelink $\neq$, Jos A. Karlast, \\ Marina C. Burger†, Frits R. Mooi $\dagger$ and Albert D.M.E. Osterhaus $\ddagger$
}

Salmonella typhimurium aroA strains (SL3261), expressing high levels of the Gag protein of feline immunodeficiency virus (FIV) fused with maltose binding protein (SL3261-MFG), were constructed using an invertible promoter system that allows the stable expression of heterologous antigens at levels toxic for bacteria. A SL3261 strain expressing the B subunit of cholera toxin by a similar system (SL3261-CtxB) served as a control in FIV-immunization experiments. Cats immunized once orally or intraperitoneally with SL3261-MFG or SL3261-CtxB all developed serum antibodies to SL3261 lipopolysaccharide and against maltose binding protein or the $B$ subunit of cholera toxin, respectively. Two intraperitoneal immunizations with $S L 3261-M F G$ also resulted in the development of Gag specific serum antibodies. Two oral immunizations with SL3261$M F G$ primed for a Gag specific response, which was demonstrated upon FIV challenge. All challenged cats became infected and no significant differences in viral loads were found between SL3261-MFG and SL3261-CtxB immunized cats. (C) 1997 Elsevier Science Ltd.

Keywords: FIV; Salmonella typhimurium; invertible promoter

Feline immunodeficiency virus (FIV) infection of cats shows many similarities with human (HIV) and simian immunodeficiency virus (SIV) infections. It infects its natural host persistently, is $T$ lymphotropic, causes a progressive loss of $\mathrm{CD}^{+} \mathrm{T}$ cells, can infect macrom phages and astrocytes, and eventually causes severe immunodeficiency or feline AIDS $^{1-6}$. Because of these similarities, FIV infection of cats is considered a useful small-animal model for the evaluation of vaccine strategies relevant for controlling HIV-1 infection of humans.

In the search for effective lentivirus vaccines different strategies like inactivated complete virus ${ }^{7}$, subunits ${ }^{8-12}$, peptides $^{13}$, live attenuated virus ${ }^{14-17}$, viral carriers ${ }^{18-20}$, bacterial carriers ${ }^{21.22}$ and nucleic acid immunizations $^{23,24}$ are being explored. In the FIV-cat system, vaccination of cats with paraformaldehyde fixed $T$ cells (FL-4 cells) persistently infected with FIV and with paraformaldehyde inactivated FIV derived from the

*Present address: School of Biological and Medical Sciences, University of St Andrews, Irvine Building, North Street, St Andrews, KY16 9AL, Scotland. †National Institute of Public Health and The Environment, PO Box 1, 3720 BA, Bilthoven, The Netherlands. †Department of Virology, Erasmus University Rotterdam, Dr. Molewaterplein 50, 3015 GE, Rotterdam, The Netherlands. \$To whom correspondence should be addressed. (Received 30 May 1996; revised 4 November 1996; accepted 27 November 1996) same cells, proved to be protective against homologous and to a lesser extent heterologous challenge ${ }^{25,26}$. In the SIV-macaque system, vaccination with whole inactivated virus induced partial protection against challenge with PBMC from a SIVmac infected macaque ${ }^{27}$. Earlier reported protection against challenge with cell-free virus after immunizing with inactivated whole SIVmac was almost certainly mediated by the immune response to cellular proteins incorporated into both the immunogen and the challenge viruses ${ }^{27,28}$. To date, the most cffective protection of macaques against SIV infection has been obtained with live attenuated SIV ${ }^{14,29}$. However, safety issues are still a major subject of debate ${ }^{17}$.

Live recombinant carriers like pox-viruses, BCG and attenuated Salmonella strains are being evaluated as alternative approaches for lentivirus vaccine development. Attenuated Salmonella strains have been used successfully to present heterologous bacterial ${ }^{30,31}$, viral $^{32-34}$ and protozoal ${ }^{35-37}$ antigens to the immune system of mammals. Systemic humoral and cellular responses, including class I restricted cytotoxic $\mathbf{T}$ lymphocytes (CTL), and mucosal humoral responses have been shown to result from vaccination with recombinant Salmonella strains ${ }^{35,38-41}$.

The development of Salmonella bacteria as carriers for heterologous antigens has largely been hampered by problems with stability of expression or production levels caused by the toxicity of the antigens for the 
pIP:
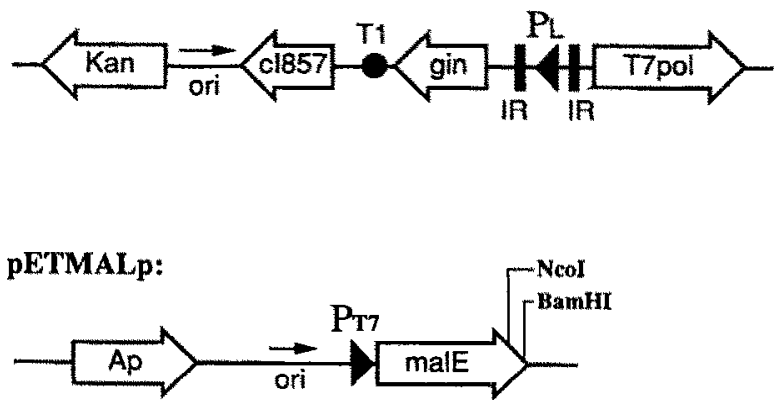

Figure 1 The two plasmid invertible promoter system. $P_{L}$, leftward promoter of bacteriophage lambda; $I R$, inverted repeat; $T 1, \operatorname{rnB} T 1$ transcription terminator; gin, invertase gene; c1587, phage lambda temperature sensitive repressor protein gene; Kan, kanamycin resistance gene; $\mathrm{Ap}$, ampicillin resistance gene; malE, gene coding for maltose binding protein; T7pol, T7 RNA polymerase gene; $P_{T 7}$, gene-10 promoter of bacteriophage T7. The invertible promoter of olP controls transcription of the T7 RNA polymerase gene, which in turn directs transcription of a gene located under control of the $P_{T T}$ promoter on a second plasmid [e.g. pETMALp, pETMALgag (not shown) or pT7ctxB (not shown)]. In this study four different pIPvectors ( $\mathrm{PIP2},-3,-4$ and -5 ) were used. The vector pIP3 $(=p Y Z 27 G P)$ differs from pIP2 (=pYZ27bGP) by having an additional adenine in the untranslated leader sequence of the gin gene. The vectors pIP4 and pIP5 are derivatives from pIP2, respectively pIP3, in which the $015 \mathrm{~A}$ origin of replication (or) that results in an intermediate copy number, is replaced by the ori and partitioning (pant region of the low copy number plasmid $\mathrm{pSC101}$. The par region ensures equal distribution of the plasmid over the daughter cells during cell division

producing Salmonella strains. Especially expression of non-bacterial antigens may cause problems due to different codon usage or the presence of toxic (e.g. hydrophobic) sequences. Therefore we $e^{42-45}$ developed a system that allows the stable expression of antigens at levels toxic for individual bacteria. The system is based on an invertible promoter that controls the expression of $\mathrm{T} 7$ RNA polymerase. A single promoter inversion results in expression of T7 RNA polymerase, which in turn directs expression from genes located under the control of a $\mathrm{T} 7$ promoter present on another vector in the same cell (Figure 1). The key feature of the system is that the promoter controlling the T7 RNA polymerase expression inverts with a frequency that results in toxic levels of antigen expression in only a sub-population of the bacteria. Therefore the major part of the bacterial population will not be affected by expression of the heterologous antigen and will continuously segregate new antigen-producing bacteria.

Here we describe the use of this invertible promoter system to express high levels of FIV core protein as a fusion with the maltose binding protein (MBP) in the $S$ typhimurium aro $A$ vaccine strain SL 3261 and the use of this strain to induce specific immunity in cats.

\section{MATERIAL AND METHODS}

\section{Bacterial strains, plasmids and media}

Escherichia coli strain DH5a (BRL. Life Technologies, Breda, The Netherlands) was used as a host for all plasmid constructions. Before introduction into the $S$. typhimurium aroA vaccination strain SL $3261^{46}$ plasmids were passaged through the restriction deficient, modification proficient $S$. typhimurium strain SL5283, a galE503 derivative of LB5000 ${ }^{47,48}$.
Strain BL21DEpLysS ${ }^{49}$ is a lysogen of the $E$. coll strain BL21 that contains a copy of the T7 RNA polymerase gene in the chromosome under control of the IPTG inducible lacUV5 promoter ${ }^{50}$ and the pLysS plasmid which codes for T7 lysozyme; a natural inhibitor of T7 RNA polymerase. Strain BL21DEpLysS was used to express genes under the control of a T7 promoter. The T7 RNA lysozyme, encoded by pLysS, reduces the basal activity of T7 RNA polymerase in uninduced cells, thereby allowing the establishment of target genes whose basal expression would otherwise have been toxic to the cells. The vector plysS confers resistance to chloramphenicol and is compatible with plasmids containing a ColE1 origin of replication ${ }^{49}$. All bacteria were grown aerobically at $37^{\circ} \mathrm{C}$ in Luria broth (LB), unless indicated otherwise. Ampicillin was used at $100 \mu \mathrm{g} \mathrm{ml}^{-1}$ in LB agar plates and $200 \mu \mathrm{g} \mathrm{ml}^{-1}$ in liquid media. Kanamycin and chloramphenicol were used at concentrations of $50 \mu \mathrm{g} \mathrm{ml}^{-1}$ and $35 \mu \mathrm{g} \mathrm{ml}^{-1}$, respectively, in agar plates as well as in liquid media.

Construction of the plasmids pYZ27bGP (=pIP2), pYZ27GP (=pIP3), pIP4 and pIP5 has been described previously ${ }^{43,45}$. The vectors pET $3 \mathrm{xa}^{49}$ and pMal-p were purchased from Invitrogen and New England Biolabs, respectively.

\section{DNA manipulations}

Isolation of plasmid DNA, preparation of DNA fragments and ligations were carried out using standard methods ${ }^{5}$. Plasmids were introduced into bacteria by electroporation as previously described ${ }^{44}$.

\section{Construction of plasmids used in this study}

To increase the copy number of $\mathrm{pET} 3 \mathrm{xa}^{49}$ the rop gene, which negatively regulates plasmid copy numbers of ColEl based plasmids, was removed by cleavage with $B g I I I$ and PvuII, followed by blunting of the ends with T4 DNA polymerase and religation of the plasmid. From the resulting plasmid, designated pET3xa1, a number of inconvenient restriction sites were removed by cleavage with $E c o$ RI and $E c o$ RV followed by blunting with T4 DNA polymerase and religation. The resulting plasmid was designated pET3xa2. The malE gene, which codes for precursor maltose binding protein (preMBP), was obtained by PCR using pMal-p (cat

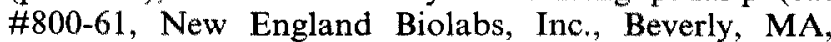
USA) as template and the oligo nucleotides $5^{\circ}$. CGAGCATATGAAAATAAAAACAGGTGCACG-3' and 5'GAATTCAGGCCTACCC TCGATGGATCC-3' as amplimers. The first amplimer was designed to introduce a NdeI site (underlined) at the position of the ATG start codon of malE. The second amplimer overlapped partially with the multiple cloning site (MCS) of pMAL-p, so that the PCR product would contain the 5 -part of the MCS, which includes a unique KpnI site. The PCR product was cleaved with $N d e I$ and $K p n I$ and cloned into the corresponding sites of pET3xa2 to generate pETMALp (Figure 1). In this plasmid transcription of the malE gene is under the control of the T7 promoter.

The vector pETMALgag was constructed by replacing the small NcoI-BamHI fragment of pETMALp (Figure 1 ) by the Ncol-BamHI fragment of pMAL-gag, which contained the 3 '-end of the malE gene in frame 
Table 1 SL3261 strains used in this study

\begin{tabular}{lll}
\hline Strain & Plasmids & $\begin{array}{l}\text { Heterologous } \\
\text { antigen }\end{array}$ \\
\hline SL3261 & no & no \\
SL3261(pETMALgag) & pETMALgag & no \\
SL3261-MFG2 & pETMALgag+pIP2 & MFG \\
SL3261-MFG3 & pETMALgag+pIP3 & MFG $^{a}$ \\
SL3261-MFG4 & pETMALgag+pIP4 & MFG $^{a}$ \\
SL3261-MFG5 & pETMALgag+pIP5 & MFG $^{a}$ \\
SL3261-CtxB & pT7ctxB+pIP2 & CtxB \\
\hline
\end{tabular}

a MFG, fusion protein of Maltose binding protein and FIV-Gag

${ }^{\circ} \mathrm{Ctxb}, \mathrm{B}$ subunit of cholera toxin

with the complete coding part of the gag gene of the molecular FIV clone 19k1. In pETMALgag, transcription of the malE-gag fusion is under the control of the $\mathrm{T} 7$ promoter.

\section{Western blot analysis of bacteria}

For Western blot analysis SDS-PAGE was immediately followed by transfer of the proteins to nitrocellulose. Blots were incubated for $30 \mathrm{~min}$ at room temperature with blocking buffer (BB) $[0.5 \%$ Tween- 20 and $0.5 \%$ low fat milk powder in PBS]. Subsequently, the blots were incubated for $1 \mathrm{~h}$ at room temperature with serum of an experimentally infected SPF cat (cat 89176), diluted 100 times in BB. After washing 3 times over a period of $30 \mathrm{~min}$ in PBS containing $0.5 \%$ Tween20 , the blot was incubated for $1 \mathrm{~h}$ at room temperature with a biotinylated anti-cat IgG monoclonal (Sigma Immuno Chemicals, clone CT-21, cat.nr. B-226) diluted in BB. After washing, the blot was incubated for $30 \mathrm{~min}$ at room temperature with alkaline phosphatase conjugated ExtrAvidin (Sigma Immuno Chemicals, cat.nr. E2636) diluted in BB. Finally the blot was washed three times, soaked for $10 \mathrm{~min}$ in substrate buffer $(0.1 \mathrm{M}$ Tris pH 9.5, 0.1 M NaCl, 0.05 $\mathrm{M} \mathrm{MgCl}_{2}$ ) and developed in substrate buffer containing Nitro Blue Tetrazolium (NBT) and 5-Bromo-4-Chloro-3-Indolyl Phosphate (BCIP).

\section{Detection of antigen expression by electron microscopy}

To obtain an indication of the percentage of bacteria of strain SL3261-MFG4 (Table I) that, due to a promoter inversion, expressed the MBP-Gag fusion protein, bacteria were grown in the presence of ampicillin and kanamycin until they reached the logarithmic phase. Subsequently, the bacteria were spun down $(13,000 \mathrm{rpm})$ for $2 \mathrm{~min}$, washed once with ice cold PBS and fixed with $4 \%$ paraformaldehyde in $0.1 \mathrm{M} \mathrm{NaCa}-$ codylate (pH 7.4). Then the bacteria were transferred to $2 \%$ gelatine, impregnated in $2.3 \mathrm{M}$ sucrose and frozen in liquid nitrogen. Finally ultra thin cryosections were made. The cryosections were subjected to immunogold labelling using the Gag specific moAB $2-11^{52}$ diluted $100 \times$ in PBS containing $0.5 \%$ BSA and $0.1 \%$ gelatine, and protein A conjugated to gold particles with a diameter of $10 \mathrm{~nm}$ (Aurion, Wageningen, The Netherlands, nr. 110.111) diluted $20 \times$ in the same buffer. The sections were stained and embedded into methyl cellulose according to the method of Tokuyasu ${ }^{53}$. Subsequently, the sections were analysed by transmission electron microscopy (Phillips EM400). Bacteria were arbitrarily classified according to the amount of labelling. For this determination only complete longitudinal cross sections of bacteria were used.

\section{Plasmid stability of bacterial strains during growth in thymocytes}

The assay for determination of plasmid stability of SL3261 strains after invasion of eukaryotic cells was essentially performed as described previously ${ }^{45}$. In short, thymocytes derived from a specified pathogen free (SPF) cat were stimulated for 3 days with Concanavalin A, washed and subsequently maintained in culture medium (RPMI 1640 [Gibco] supplemented with 10\% [v/v] FCS, $2 \mathrm{mM}$ L-glutamine, penicillin [100 $\left.\mathrm{IU} \mathrm{ml}^{-1}\right]$, streptomycin $\left[100 \mu \mathrm{g} \mathrm{ml}^{-1}\right]$, L-glutamine [2 $\left.\mathrm{mM}\right]$ and IL2 [100 IU ml ${ }^{-1}$, Cetus) at $37^{\circ} \mathrm{C} / 5 \% \mathrm{CO}_{2}$. About $10^{8}$ bacteria from logarithmic phase cultures were added to $10^{6}$ thymocytes in a total volume of $1 \mathrm{ml}$ RPMI 1640 without any additives. After $2 \mathrm{~h}$ incubation at $37^{\circ} \mathrm{C}$ the cells were washed and subsequently maintained at $37^{\circ} \mathrm{C} / 5 \% \mathrm{CO}_{2}$ in $10 \mathrm{ml}$ culture media containing gentamicin $\left(50 \mu \mathrm{g} \mathrm{ml}^{-1}\right)$ to kill extracellular bacteria. After $24 \mathrm{~h}$ the plasmid stability was determined by lysing the thymocytes and comparing the number of CFUs that could be recovered on plates without and with the appropriate antibiotics.

\section{Immunization and FIV challenge of cats}

For immunization, bacteria from logarithmically growing cultures were harvested by centrifugation, washed, and resuspended in PBS. Subsequently, six months old specified pathogen free (SPF) cats, without detectable antibody levels against Salmonella LPS or

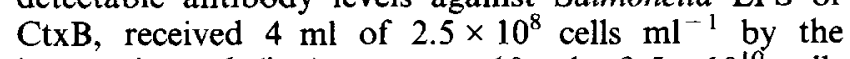
intraperitoneal (i.p.) route or $10 \mathrm{ml}$ of $5 \times 10^{10}$ cells $\mathrm{ml}^{-1}$ directly into the stomach to simulate oral administration. This "oral" immunization was performed with anaesthetized cats using a syringe connected to a thin tube that reached into the stomach. Just prior to oral administration of the bacteria, gastric juices were neutralized by administration of $10 \mathrm{ml} 10 \% \mathrm{NaHCO}_{3}$, using the same device.

Two cats were immunized with SL3261 expressing Gag, one cat by the oral route and the other by the i.p. route. The primary immunization (week 0) was performed with SL3261-MFG4, whereas the secondary immunization (week 9) was performed with equal amounts of strains SL3261-MFG2 and SL3261-MFG4 (Table 1). As a control, two cats were immunized with the CtxB expressing strain SL3261-CtxB (Table 1) at week 0 and 9 . Again, one cat was immunized by the oral route and the other by the i.p. route. Eighteen weeks after the primary immunization all cats were challenged intramuscularly with 30 ID50 of the molecular FIV clone $19 \mathrm{k} 1^{54}$. Serum samples were taken at $1,2,3,4,5$, $9,10,13$ and 15 weeks after the primary immunization, immediately prior to FIV challenge and 4, 7, 10, 14, 19, $24,28,33$ and 67 days post challenge.

\section{Detection of FIV infection}

Peripheral blood mononuclear cells (PBMC) were isolated from heparinized blood and cultured in limiting dilutions as previously described ${ }^{54}$ to enumerate percentages of FIV infected cells. The presence of FIV 
antigen in culture supernatants was detected with a FIV antigen capture ELISA as previously described ${ }^{55}$.

\section{ELISAs}

LPS-ELISA. The detection of S. typhimurium LPS specific antibodies was essentially performed as previously described ${ }^{44}$. The incubation step with HRP conjugated anti-mouse antibody was replaced by an incubation for $90 \mathrm{~min}$ at $37^{\circ} \mathrm{C}$ with a biotinylated anti-cat IgG monoclonal antibody (Sigma Immuno Chemicals, clone CT-21, cat.nr. B-226) diluted 1:1000, followed by incubation for $1 \mathrm{~h}$ at $37^{\circ} \mathrm{C}$ with a streptavidin-biotin-HRP complex (cat.nr. RPN1051, Amersham) also diluted 1:1000. The titer was defined as the highest dilution of test samples at which the O.D. 450 was higher than the mean O.D. $450+3$ times S.D. of pre-immune sera.

CtxB-ELISA. The ELISA for the detection of CtxB specific antibodies differed from the LPS-ELISA in the coating step, which was performed in PBS containing $5.0 \mu \mathrm{g} \mathrm{ml}^{-1} \mathrm{CtxB}$ (List Biological Labs, Campbell, CA, USA) and the dilutions of the biotinylated anti-cat IgG monoclonal antibody $(1: 2000)$ and the streptavidin HRP-conjugate $(1: 2500)$. In addition the ELISA-buffer in which the cat sera were diluted, was supplemented with $1 \%$ SL3261 sonificate prepared from a 50 times concentrated $\mathrm{o} / \mathrm{n}$ bacterial culture to reduce background reactions. The titer was defined as the highest dilution of test samples at which the O.D. 450 was at least three times higher than that of the corresponding serum dilution of the control cat immunized in a similar way with SL3261 expressing MBP-Gag instead of CtxB.

$M B P-E L I S A$. The ELISA for the detection of MBP specific antibodies was performed identical to that for CtxB except that for the coating step $3.0 \mu \mathrm{g} \mathrm{ml}^{-1} \mathrm{MBP}$ was used. The MBP was isolated from strain DH5a(pMALc) by affinity chromatography with maltose-Sepharose using a commercially available kit (Protein Fusion and Purification System, cat \#800, New England Biolabs, Inc., Beverly, MA, USA). The titer was defined as the highest dilution of test samples at which the O.D. 450 was at least two times higher than that of the corresponding serum dilution of the control cat immunized in a similar way with SL3261 expressing CtxB instead of MBP-Gag.

Gag-ELISA. Antibody titers against p17 and p24 core proteins were determined using a commercially available ELISA (FIV-p24/p17 antibody test kit, cat. nr. F1002-AB01, European Veterinary Laboratory BV, Woerden, The Netherlands).

\section{RESULTS}

\section{Expression of FIV-Gag}

For use in the two plasmid invertible promoter system (Figure 1), the malE gene was placed under the control of the T7 promoter. The resulting plasmid, designated pETMALp (Figure 1), was transferred to the $E$. coli strain BL21DEpLysS which contains on its chromosome the T7 RNA polymerase gene under control of the IPTG inducible lacUV5 promoter.

\section{0}

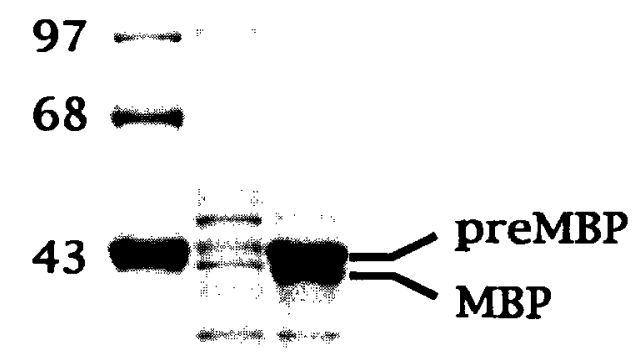

29

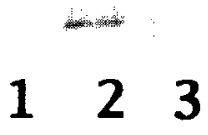

Figure 2 Expression of MBP by BL21DEpLysS(pETMALp). Five hours after the addition of $1 \mathrm{mM}$ IPTG to logarithmically growing bacteria, cells were harvested and total bacterial lysates were subjected to SDS-PAGE followed by staining of the gel. Lanes: 1. molecular weight markers; 2. BL21DEpLysS; 3. BL21DEpLysS (pETMALp). Numbers on the left refer to the molecular sizes of the marker proteins in $\mathrm{kDa}$

IPTG-induction of the T7 RNA polymerase gene in BL21DEpLysS(pETMALp) resulted in the expression of the malE gene (Figure 2). A prominent band with a $\mathrm{Mw}$ corresponding to preMBP, as well as a weaker band with a Mw corresponding to MBP from which the signal sequence had been cleaved-off, were visible on a Coomassie Blue stained SDS-PAGE gel.

To obtain high expression levels of the gag gene of the molecular clone FIV $19 \mathrm{k} 1$, it was cloned in frame with the malE gene of pETMALp and the resulting plasmid was designated pETMALgag. The plasmid pIP2 (=pYZ27bGP) (Figure 1) contains the T7 RNA polymerase gene under control of an invertible $\mathrm{P}_{L^{-}}$ promoter. S. typhimurium strain SL3261, harbouring pETMALgag in combination with pIP2, designated SL3261-MFG2, expressed high amounts of the MBP. Gag fusion protein (Figure 3A). The presence of the Gag-moiety of this fusion protein was confirmed by Western blotting which shows the full-length MBP-Gag band and a number of break-down products (Figure 3B).

\section{Inversion frequency and plasmid stability}

Previously ${ }^{45}$ it had been demonstrated that pIP3, which differs from $\mathrm{pIP} 2$ by having an extra nucleotide in the untranslated leader sequence of gin, reveals slightly lower expression levels of genes under the control of a T7-promoter than pIP2. The vectors pIP4 and pIP5 are lower copy number derivatives of pIP2 and pIP3, respectively, which reveal significantly lower expression levels than the parental plasmids. The pIP-vectors were analyzed by SDS-PAGE (Figure 4A) and Western blotting (Figure 4B). Three individual clones were tested for each of the plasmid combinations. The highest MBP-Gag production was obtained for SL3261-MFG2, followed by SL3261-MFG3 and SL3261-MFG4, which reveal comparable expression levels, and finally SL3261-MFG5. 


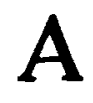

B

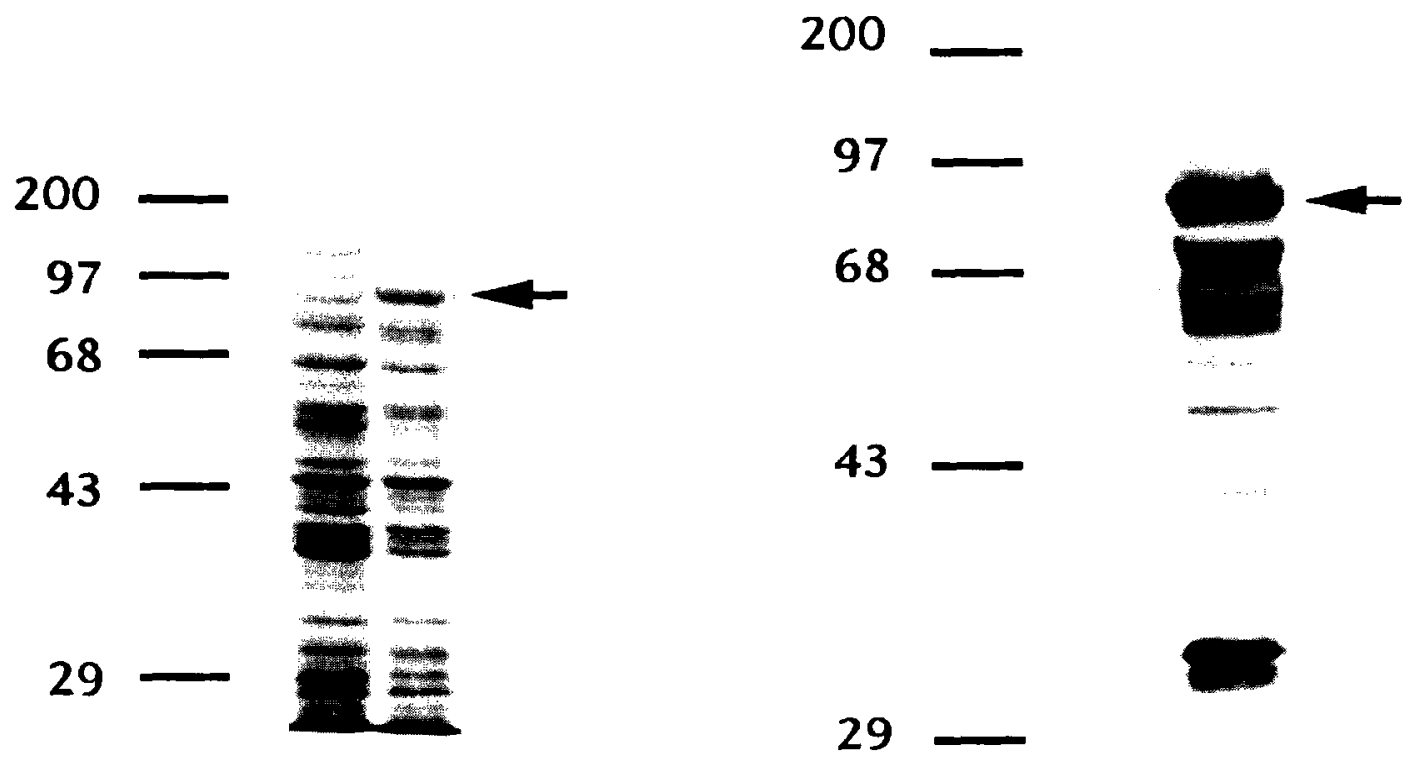

12

12

Figure 3 Expression of MBP-Gag by SL3261 containing the two-plasmid invertible promoter system. Cells were grown at $37^{\circ} \mathrm{C}$, lysed and subjected to SDS-PAGE. Lanes: 1 . SL3261; 2. SL3261-MFG2. (A) Coomassie-blue stained SDS-PAGE gel; (B) Western blot using serum of an experimentally FIV-infected SPF cat. The arrow indicates the position of the full-length MBP-Gag fusion protein

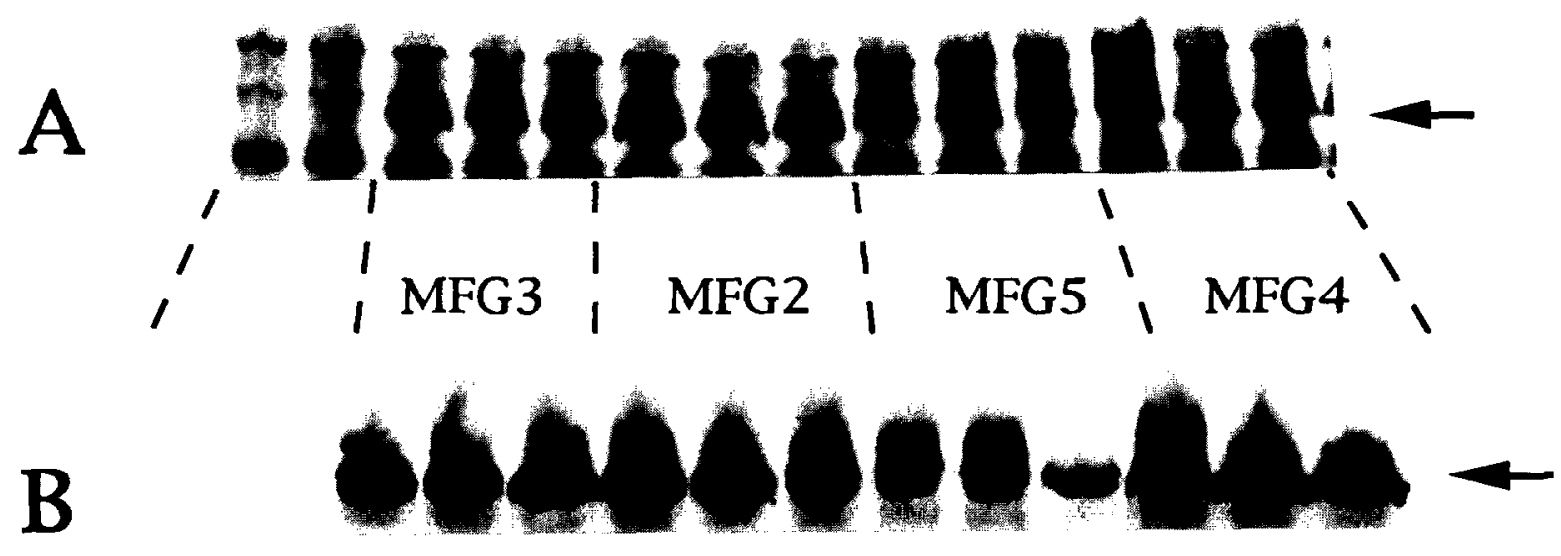

\section{$\begin{array}{lllllllllllllll}1 & 2 & 3 & 4 & 5 & 6 & 7 & 8 & 9 & 10 & 11 & 12 & 13 & 14\end{array}$}

Figure 4 Expression of MBP-Gag by different SL3261-MFG strains. Total cell lysates of bacteria grown at $37^{\circ} \mathrm{C}$ are shown. For each strain three individual clones were analysed. Lanes: 1. SL3261; 2. SL3261 (pETMALgag); 3-5. SL3261-MFG3; 6-8. SL3261-MFG2; 9-11. SL3261MFG5; 12-14. SL3261MFG4; (A) Coomassie-blue stained SDS-PAGE gel; (B) Western blot using serum of an experimentally FIV-infected SPF-cat. The arrow indicates the position of the MBP-Gag fusion protein. Only the relevant part of the SDS-PAGE and WB is shown

The plasmid stability of SL3261 strains after growth in eukaryotic cell lines gives an indication of the in vivo plasmid stability ${ }^{45}$. Therefore the plasmid stability of the SL3261-MFG strains was determined in cat thymocytes cultured in vitro (Table 3). In this invasion assay pETMALgag alone was stably maintained in SL3261, but the combinations of pETMALgag with pYZ27bGP (=pIP2), and pYZ27GP (=pIP3) were not. The majority of the bacteria harbouring one of these combinations lost one or both plasmids within $24 \mathrm{~h}$. Furthermore, the bacteria that still contained both plasmids, appeared to be mutants that did not express the fusion protein. In contrast, the combinations of pETMALgag with pIP4 or pIP5 were relatively stable and all the tested bacteria still expressed the MBP-Gag fusion protein.

Of the two stably expressing strains the highest expression levels were obtained with SL3261-MFG4. To obtain an indication of the percentage of the cells, that 


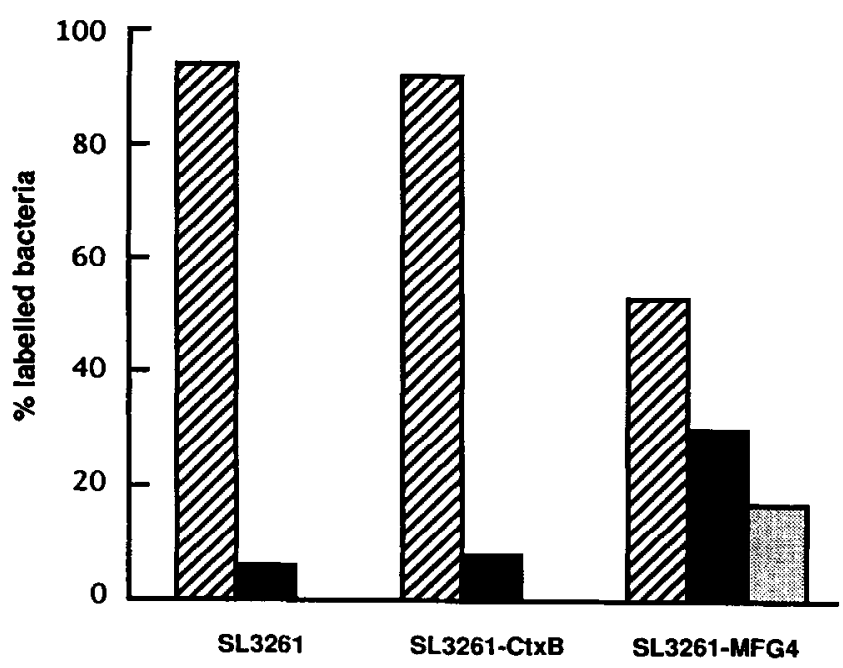

Figure 5 Percentage immunogold labelled bacteria using a Gag specific monocional antibody. Logarithmically growing bacteria were fixed, immunogold labelled and analysed by transmission electron microscopy. Bacteria were classified according to the amount of goldparticles/cell: 0 (striped); 1-3 (black); more than 3 (dotted)

Table 2 Immunization schedule of cats with SL3261 strains expressing heterologous antigens

\begin{tabular}{lllll}
\hline Cat (no) & Strain & Route & $\begin{array}{l}\text { Immunizations } \\
\text { (week) }\end{array}$ & $\begin{array}{l}\text { Challenge }^{a} \\
\text { (week) }\end{array}$ \\
\hline 1 & SL3261-CtxB & oral & 0 and 9 & 18 \\
2 & SL3261-CXXB & i.p. & 0 and 9 & 18 \\
3 & SL3261-MFG & oral & 0 and 9 & 18 \\
4 & SL3261-MFG & i.p. & 0 and 9 & 18
\end{tabular}

${ }^{a}$ Challenge was performed i.m. with 30 cat ID50 of the molecular clone IV 19k1

expressed the MBP-Gag fusion protein in this strain, bacteria from logarithmic growth cultures were fixed, immunogold labelled on ultra-thin cryosections and analysed by means of transmission electron microscopy. Bacteria were arbitrary classified according to the amount of labelling (Figure 5). Of the cells of the negative control strains SL3261 and SL3261-CtxB, 94\% and $92 \%$ were not labelled, respectively. The remaining $6 \%$ and $8 \%$ respectively, were labelled with only one to three gold particles. Of strain SL3261-MFG4 53\% of the cells were not labelled, $30 \%$ contained one to three gold particles and $17 \%$ contained more than 3 particles, with an average of 10.5 particles/bacterium. Taking the $7 \%$ background labelling of the control strains into consideration, the percentage cells from strain SL3261MFG4 expressing MBP-Gag is approximately $40 \%$ $(=30-7+17)$ of the total population.

\section{Immunogenicity of SL3261-MFG and SL3261-CtxB in the cat}

Two cats were immunized with SL3261-MFG4 and two cats with strain SL3261-CtxB, which previously induced high titers of $\mathrm{CtxB}$ specific antibodies in mice ${ }^{45}$. Within each group one of the cats was immunized orally and the other one intraperitoneally (i.p.) (Table 2). All animals developed antibodies to $S$. typhimurium LPS within one week after the first immunization (Figure 6a). After administration of SL3261-CtxB, high anti-CtxB serum titers were induced (Figure 6b). After the primary immunization with SL3261-MFG4, considerable antiMBP IgG titers were induced in the i.p. immunized cat (Figure 6c). The orally immunized cat developed a weak specific IgG response after the first immunization, but the second immunization at week 9 resulted in a considerably increased response.

After the primary immunization with SL3261-MFG4, no antibodies specific for the Gag-moiety of the MBPGag fusion protein could be detected. This strain was selected for the primary immunization, because the plasmids in this strain were relatively stable in the invasion assay (see Table 3). The second immunization was performed with equal amounts of SL3261-MFG4 and SL3261-MFG2. Although the plasmid combination of SL3261-MFG2 was not stably maintained in the invasion assay, it was incorporated in the second immunization because it expressed higher levels of MBP-Gag. The idea was that SL3261-MFG2 would present a higher amount of MBP-Gag early in infection, while SL3261-MFG4 would give a lower but more stable expression. One week after the second immunization Gag-specitic antibodies were detected in the serum of the cat immunized by the i.p. route (Figure 6d). No Gagspecific antibodies were detected in the scrum of the orally immunized cat.

To determine whether immunization with SL3261MFG had induced protective cellular immune responses, all cats were challenged intramuscularly with 30 ID 50 of the homologous molecular clone FIV 19k1, eighteen weeks after the first immunization. Between 14 to 19 days post challenge (p.c.) all the animals had developed a persistent viraemia (Table 4). No significant differences in viral load were observed between the cats immunized with SL3261-MFG or SL3261-CtxB (Table 5). Both cats immunized with the SL3261-MFG strains developed an anamnestic response to Gag as antibody titers to Gag started to rise two weeks earlier in these cats than in the cats immunized with SL3261-CtxB (Figure 6d).

\section{DISCUSSION}

In the present paper we have shown that the $S$. typhimurium strain SL3261 can be used efficiently as a vector to present heterologous antigens to the feline immune system. Cats immunized with SL3261-MFG developed a Gag specific immune response, but were not protected from intramuscular challenge with the homologous molecular clone FIV 19k1.

The development of candidate vaccines based on recombinant Salmonella as live carriers, has largely been hampered by the inability to stably express heterologous antigens at levels that are toxic for the producing bacteria. However, we previously ${ }^{45}$ described a two plasmid invertible promoter system which may solve this problem. The system is based on the pIP-vectors which contain the T7 RNA polymerase gene under control of a promoter that inverts at random. When the promoter inverts to the ON position, T7 RNA polymerase is expressed which in turn directs expression of the gene of interest that has been positioned under the control of a T7 promoter on a second plasmid. The system can be stably maintained when a pIP vector is used that results in toxic antigen expression in only a minor part of the bacterial population.

In the present study we used the invertible promoter vectors pIP2 $(=\mathrm{pYZ27bGP})$, pIP3 $(=\mathrm{pYZ27GP})$, pIP4 

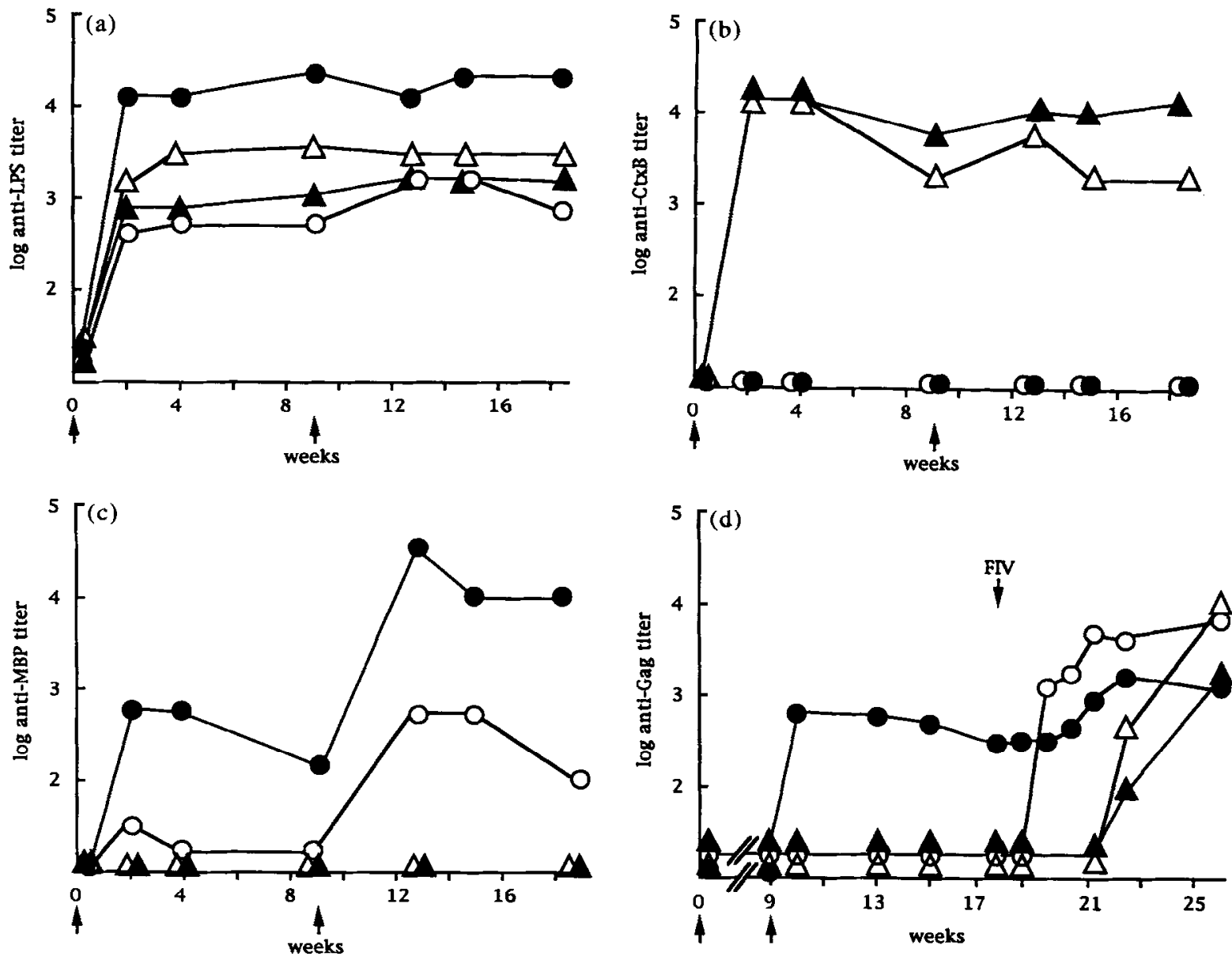

Figure 6 The $\operatorname{lgG}$ antibody titers in cat sera immunized with recombinant S.typhimurium vaccine strains and challenged with FIV. Cats were immunized orally (open symbols) or i.p. (closed symbols) at week 0 and 9 with SL3261-MFG (circles) or SL3261-CtxB (triangles). Eight weeks after the booster immunization the cats were challenged intramuscularly with a dose of 30 cat ID50 FIV. (a) LPS-specific antibody titer; (b) CtXB-specific antibody titer; (c) MBP-specific antibody titer; (d) core proteins p17/p24-specific antibody titer.

Table 3 Stability of recombinant SL3261 strains in cat thymocytes cultured in vitro

\begin{tabular}{lll}
\hline \multirow{2}{*}{ strain } & \multicolumn{2}{l}{ Stability } \\
\cline { 2 - 2 } & plasmids & expression $^{b}$ \\
\hline SL3261 (pETMALgag) & $99.5 \pm 0.5 \%$ & \\
SL3261-MFG2 & $17 \pm 2 \%$ & $0 / 2$ \\
SL3261-MFG3 & $7 \pm 2 \%$ & $0 / 2$ \\
SL3261-MFG4 & $71 \pm 21 \%$ & $4 / 4$ \\
SL3261-MFG5 & $79 \pm 19 \%$ & $3 / 3$
\end{tabular}

a Cat thymocytes were infected with the different bacterial strains and cultured for $24 \mathrm{~h}$ in the presence of gentamicin to kill extracellular bacteria. The plasmid stability was determined by lysing the thymocytes and comparing the number of CFU on LB-agar plates with and without all the appropriate antibiotics.

${ }^{\circ}$ Number of MBP-Gag expressing colonies/total number of tested colonies harbouring both plasmids.

and pIP5 to express the Gag protein of FIV as a fusion product with MBP. $S$. typhimurium aroA strains SL3261-MFG (Table 1) expressed high levels of the MBP-Gag fusion protein. The highest expression levels were obtained with SL3261-MFG2 followed by SL3261MFG3 and SL3261-MFG4, which revealed similar expression levels, and finally SL3261-MFG5. Of the different SL3261-MFG strains, only SL3261-MFG4 and SL3261-MFG5 stably maintained their plasmids after invasion of a cat thymocyte cell line (Table 3). Although
Table 4 Detection of FIV in cat PBMCs after challenge

\begin{tabular}{llllllll}
\hline $\begin{array}{l}\text { Immunization: } \\
\text { stain/route }\end{array}$ & \multicolumn{7}{l}{ Presence of FIV at day (p.c.): } \\
\cline { 2 - 8 } & 4 & 7 & 10 & 14 & 19 & 24 & 60 \\
\hline SL3261-MFG/oral & - & - & - & + & + & + & + \\
SL3261-MFG/i.p. & - & - & - & + & + & + & + \\
SL3261-CtxB/oral & - & - & - & - & + & + & + \\
SL3261-CtxB/i.p. & - & - & - & - & + & + & +
\end{tabular}

PBMC were stimululated with $10 \mu \mathrm{g} \mathrm{ml}^{-1}$ ConA for three days, washed and maintained in culture medium containing $100 \mu / \mathrm{ml}^{-1}$ $r-I L-2$. The presence of FIV-antigen was detected using an antigen capture ELISA

Table 5 Viral load after FIV challenge

\begin{tabular}{|c|c|c|c|c|}
\hline \multirow{2}{*}{$\begin{array}{l}\text { Immunization: } \\
\text { antigen/route }\end{array}$} & \multicolumn{4}{|c|}{ Infected cells per $10^{6}$ PBMC (days p.c.): } \\
\hline & 14 & 19 & 33 & 67 \\
\hline $\begin{array}{l}\text { SL3261-MFG/oral } \\
\text { SL3261-MFG/i.p. } \\
\text { SL3261-CtxB/oral } \\
\text { SL3261-CtxB/i.p. }\end{array}$ & $\begin{array}{l}\text { NT } \\
<12.5 \\
<12.5 \\
<12.5\end{array}$ & $\begin{array}{l}12.5 \\
\text { NT } \\
\text { NT } \\
\text { NT }\end{array}$ & $\begin{array}{l}58 \\
133 \\
79 \\
79\end{array}$ & $\begin{array}{l}75 \\
375 \\
150 \\
112\end{array}$ \\
\hline
\end{tabular}

SL3261-MFG3 and SL3261-MFG4 expressed similar amounts of the MBP-Gag fusion protein, indicating the presence of comparable percentages of antigen 
expressing bacteria, a striking difference in plasmid stability between both strains was observed. The higher plasmid stability of SL3261-MFG4 compared to SL3261-MFG3, is most likely the result of the partitioning (par) region present on pIP4 which is absent on pIP3. This par region ensures equal distribution of the plasmid copies over the daughter cells during cell division, what greatly enhances plasmid stability ${ }^{56}$

Immunogold labelling of SL3261-MFG4 demonstrated that about $40 \%$ of the bacteria expressed MBPGag (Figure 5). This does not mean that all these expressing bacteria actually contain a pIP plasmid with the $P_{L}$ promoter in the $O N$ position. It may be speculated that a number of these cells have been derived from cells that divided after a promoter inversion occurred, but before antigen expression reached a level that prevented further cell divisions.

The $S$. typhimurium vaccination strain SL3261 appeared to be immunogenic in cats. After i.p. as well as after oral immunization, high specific antibody titers to $S$. typhimurium LPS were induced. Moreover, SL3261 can also be used as a vector to present heterologous antigens to the immune system of cats, as high serum antibody titers were induced to $\mathrm{CtxB}$ and $\mathrm{MBP}$. The responses to FIV Gag were considerably weaker. A second immunization was necessary to induce detectable Gag specific serum antibodies upon i.p. immunization. After two oral immunizations no Gag-specific antibodies were detected, but the immune system had clearly been primed for Gag protein recognition, as after FIV challenge Gag-specific antibodies could be detected two weeks earlier than in the control cats. It is unlikely that this is the result of enhancement of FIV infection, as we observed with other FIV vaccine candidates ${ }^{57}$, since the FIV loads of this cat at 33 and 67 days post challenge were even lower than those of the control cats. It should be stressed that the specific antibody responses were mainly determined as a marker to demonstrate that the heterologous antigens expressed by SL3261 are presented to the immune system of cats, since it cannot be expected that antibodies against the internal Gag proteins would neutralize FIV. In general $S$. typhimurium preferentially induces cellular immune responses, including cytotoxic $T$ cell responses ${ }^{35-38,40}$ which may contribute to protective immunity ${ }^{58}$. No FIV specific $T$ cell responses were determined in the framework of these experiments. However, if indeed Gag specific T helper and CTL responses were induced by these immunizations, they were apparently not sufficient to protect the cats against the homologous challenge with 30 CID50 FIV.

We are currently investigating the immune responses and priming effects in cats, immunized with SL3261 strains expressing the Gag and envelope proteins of FIV in order to generate a more complete immune response to FIV proteins that will hopefully result in protection.

\section{ACKNOWLEDGEMENTS}

We thank Geert van Amerongen, Herman Näring, Nico Schmidt and $\mathrm{Ab}$ van Arnhem, of the Animal Facilities Department for animal handling and $\mathrm{R}$. van Herwijnen (EVL) for performing the Gag specific ELISA. This investigation was supported by a grant of the 'Raad voor Gezondheidsonderzoek', The Haguc, The Netherlands (grant number 88-108/89027).

\section{REFERENCES}

1 Brunner, D. and Pedersen, N.C. Infection of peritoneal macrophages in vitro and in vivo with feline immunodeficiency virus. J. Virol. 1989, 63, 5483-5488

2 Ackley, C.D., Yamamoto, J.K., Levy, N., Pedersen, N.C. and Cooper, M. Immunologic abnormalities in pathogen-free cats experimentally infected with feline immunodeficiency virus. J. Virol. 1990, 64, 5652-5655

3 Dow, S.W., Poss, M.L. and Hoover, E.A. Feline immunodeficiency virus: a neurotropic lentivirus. AIDS 1990, 3, 658668

4 Torten, M., Franchini, M., Barlough, J.E., George, J.W., Mozes E., Lutz, $H$. and Pedersen, N.C. Progressive immune dysfunction in cats experimentally infected with feline immunodeficiency virus. J. Virol. 1991, 65, 2225-2230

5 Hoffmann-Fezer, G., Thum, J., Ackley, C., Herbold, M., Mysliwietz, J., Thefeld, S., Hartmann, K. and Kraft, W. Decline in $\mathrm{CD4}^{+}$cell numbers in cats with naturally acquired feline immunodeficiency virus infection. J. Virol. 1992, 66, 1484-1488

6 Siebelink, K.H.J., Chu, I., Rimmelzwaan, G.F., Weijer, K., Van Herwijnen, R., Knell, P., Egberink, H.F., Bosch, M.L. and Osterhaus, A.D.M.E. Feline immunodeficiency virus (FIV) infection in the cat as a model for HIV infection in man: FIV induced impairment of immune function. AIDS Res. Hum. Retrov. 1990, 6, 1373-1378

7 The European Concerted Action on 'Macaques models for AIDS research'. Protection of macaques against simian immunodeficiency virus infection with inactivated vaccines: comparison of adjuvants, doses and challenge viruses. Vaccine 1995, 13, 295-300

8 Mannhalter, J.W., Fischer, M.B., Wolf, H.M., Küpcü, Z., Barrett, N., Dorner, F., Eder, G. and Eibl, M.M. Immunization of chimpanzees with recombinant gp 160, but not infection with human immunodeficiency virus type 1 , induces envelope-specific Th1 memory cells. J. Inf. Dis. 1995, 171, 437-440

9 Bruck, C., Thiriart, C., Fabry, L., Francotte, M., Pala, P., van Opstal, O., Culp, J., Rosenberg, M., de Wilde, M., Heidt, P. and Heeney, J. HIV-1 envelope-elicited neutralizing antibody titres correlate with protection and virus load in chimpanzees Vaccine 1994, 12, 1141-1148

10 Vaslin, B., Le Grand, R., Vogt, G., Benveniste, O., Gras, G., Roques, P., Stoeckel, P., Salk, P.L., Salk, J. and Dormont, D. Induction of humoral and cellular immunity to simian immunodeficiency virus: what are the requirements for protection? Vaccine 1994, 12, 1132-1140

11 Hulskotte, E.G.J., Geretti, A.M., Siebelink, K.H.J., van Amerongen, G., Cranage, M.P., Rud, E.W., Norley, S.G., de Vries, P. and Osterhaus, A.D.M.E. Vaccine-induced virus neutralizing antibodies and cytotoxic $T$ cells do not protect macaques from experimental infection with simian immunodeficiency virus SIVmac32H (J5). J. Virol. 1995, 69, 6289-6296

12 Hu, S.-L, Abrams, K., Barber, G.N., Moran, P., Zarlin, J.M. Langlois, A.J., Kuller, L., Morton, W.R. and Benveniste, R.E. Protection of macaques against SIV infection by subunit vaccines of SIV envelope glycoprotein gp160. Science 1992, 255, 456-459

13 Golding, B., Inman, J., Highet, P., Blackburn, R., Manischewitz, J., Blyveis, N., Angus, R.D. and Golding, H. Brucella abortus conjugated with a gp120 or V3 loop peptide derived from human immunodeficiency virus (HIV) type 1 induces neutralizing anti-HIV antibodies, and the V3-B. abortus conjugate is effective even after $\mathrm{CD}^{+}{ }^{+}$T-cell depletion. J. Virol. 1995, 69, 3299-3307

14 Daniel, M.D., Kirchhoff, F., Czafak, S.C., Sehgal, P.K. and Desrosiers, R.C. Protective effects of a live attenuated SIV vaccine with a deletion in the nef gene. Science 1992, 258, 1938-1941

15 Putkonen, P., Walther, L., Zhang, Y.-J., Li, S.-L., Nilsson, C., Albert, J., Biberfeld, P., Thorstensson, R. and Biberfeld, G. Long-term protection against SIV-induced disease in macaques vaccinated with a live attenuated HIV-2 vaccine. Nature Medicine 1995, 1, 914-918

16 Clements, J.E., Montelaro, R.C., Zink, M.C., Amedee, A.M. Miller, S., Trichel, A.M., Jagerski, B., Hauer, D., Martin, L.N., Bohm, R.P. and Murphey-Corb, M. Cross-protective immune responses induced in rhesus macaques by immunization with attenuated macrophage-tropic simian immunodeficiency virus. J. Virol. 1995, 96, 2737-2744 
17 Dittmer, U., Niflein, T., Bodemer, W., Petry, H., Sauermann, U, Stahl-Hennig, $\mathrm{C}$. and Hunsmann, G. Cellular immune response of mesus monkeys infected with a partially attenuated nef deletion mutant of simian immunodeficiency virus. Virol. 1995, 212, 392-397

18 Galimore, A., Cranage, M., Cook, N., Almond, N., Bootman, J., Rud, E., Silvera, P., Dennis, M., Corcoran, T., Stott, J., McMichael, A. and Gotch, F. Early suppression of SIV replication by CD8+ nef-specific cytotoxic T cells in vaccinated macaques. Nature Medicine 1995, 1, 1167-1173

19 Muster, T., Ferko, B., Klima, A., Purtscher, M., Trkola, A., Schulz, P., Grassauer, A., Engelhardt, O.G., García-Sástre, A., Palese, $P$. and Katinger, $H$. Mucosal model of immunization against human immunodeficiency virus type 1 with a chimeric influenza virus. J. Virol. 1995, 69, 6678-6686

20 Mossman, S.P., Bex, F., Berglund, P., Arthos, J., O'Niel, S.P., Riley, D., Maul, D.H., Bruck, C., Momin, P., Burny, A., Fultz, P.N. Mullins, J.I., Liljeström, P. and Hoover, E.A. Protection against lethal simian immunodeficiency virus SIVsmmPBj14 disease by a recombinant Semliki Forest virus gp160 vaccine and by a gp120 suburit vaccine. J. Virol. 1996, 70, 1953-1960

21 Fouts, T.R. Lewis, G.K. and Hone, D.M. Construction and characterization of a Salmonella typhi-based human immunodeficiency virus type 1 vector vaccine. Vaccine 1995, 13, 561-569

22 Winter, N., Lagranderie, M., Gangloff, S., Leclerc, C., Gheorghiu, M. and Gicquel, B. Recombinant BCG strains expressing the SIVmac251 nef gene induce proliferative and CTL responses against nef synthetic peptides in mice. Vaccine 1995, 13, 471-478

23 Fuller, D.H. and Haynes, J.R. A qualitative progression in HIV type-1 glycoprotein-120 specific cytotoxic cellular and humoral responses in mice receiving a DNA-based glycoprotein-120 vaccine. AIDS Res. Hum. Retrov. 1994, 10, 1433-1441

24 Wang, B., Boyer, J.D., Gilbert, L., Dang, K.C., Ugen, K.E. Srikantan, V., Ayyvoo, V., Agadjanyan, M.G., Williams, W.V., McCallus, D., Carrano, R., Coney, L. and Weiner, D.B. DNAbased immunization against HIV-1: induction of multiple in vivo immune responses. AIDS Res. Hum. Retrov. 1995, 11, 136

25 Yamamoto, J.K., Okuda, T., Ackley, C.D., Louie, H., Pembroke, E., Zochlinski, H., Munn, R.J. and Gardner, M.B. Experimental vaccine protection against feline immunodeficiency virus. AIDS Res. Hum. Retrov. 1991, 7, 911-922

26 Yamamoto, J.K., Hohdatsu, T., Olmsted, R.A., Pu, R, Louie, H., Zochlinski, H.A. Acevedo, V., Johnson. H.M., Soulds, G.A. and Gardner, M.B. Experimental vaccine protection against homologous and heterologous strains of feline immunodeficiency virus. J. Virol. 1993, 67, 601-605

27 De Vries, P., Heeney, J.L., Boes, J., Dings, M.E.M., Hulskotte, E.G.J., Dubbes, R., Koornstra, W., ten Haaft, P., Akerblom, L., Eriksson, S., Morein, B., Norley, S. and Osterhaus, A.D.M.E. Protection of rhesus macaques from SIV infection by immunization with different experimental SIV vaccines. Vaccine 1994, 12, 1443-1452

28 Stott, E.J. Anti-cell antibody in macaques. Nature 1991, 353, 393

29 Lohman, B.L., McChesney, M.B., Miller, C.J., McGowan, E., Joye, S.M., Van Rompay, K.K., Reay, E., Antipa, L., Pedersen, N.C. and Marthas, M.L. A partially attenuated Simian Immunodeficiency Virus induces host immunity that correlates with resistance to pathogenic virus challenge. J Virol. 1994, 6B, $7021-7029$

30 Clements, J.D., Lyon, F.L., Lowe, K.L., Farrand, A.L. and El-Morshidy, S. Oral immunization of mice with attenuated Salmonella enteritidis containing a recombinant plasmid which codes for production of the B subunit of heat-labile Escherichia coli enterotoxin. Infect. Immun. 1986, 53, 685-692

31 Poirier, T.P., Kehoe, M.A. and Beachey, E.H. Protective immunity evoked by oral administration of attenuated aroA Salmonella typhimurium expressing cloned streptococcal $M$ protein. J. Exp. Med. 1988, 168, 25-32

32 Charbit, A., Martineau, P., Ronco, J., Leclerc, C., Lo-Man, R., Michel, V., O'Callaghan, D. and Hofnung, M. Expression and immunogenicity of the $V 3$ loop from the envelope of human immunodeficiency virus type 1 in an attenuated aroA strain of Salmonella typhimurium upon genetic coupling to two Escherichia coli carrier proteins. Vaccine 1993, 11, 1221-1228

33 Schödel, F., Kelly, S.M., Darrell, L., Milich, D.R. and Curtiss III, $R$. Hybrid hepatitis B virus core-pre-S proteins synthesized in avirulent Salmonella typhimurium and Salmonella typhi for oral vaccination. Infect. Immun. 1994, 62, 1669-1676

34 Tite, J.P., Gao, X.M., Hughes-Jenkins, C.M., Lipscombe, M., O'Callaghan, D. and Dougan, G. Antiviral immunity induced by recombinant nucleoprotein of influenza-A virus. III. Delivery of recombinant nucleoprotein to the immune system using attenuated Salmonella typhimurium as a live carrier. Immunol, 1990 , 70, 540-546

35 Aggarwal, A., Kumar, S., Jaffe, R., Hone, D., Gross, M. and Sadoff, J. Oral Salmonella: Malaria circumsporozoite recombinants induce specific $\mathrm{CD} 8+$ cytotoxic T cells. J. Exp. Med. $1990,172,1083-1090$

36 Sadoff, J.C., Ballou, W.R., Baron, L.S., Majarian, W.R., Brey, R.N., Hockmeyer, W.T., Young, J.F., Cryz, S.J., Ou, J., Lowell, G.H. and Chulay, J.D. Oral Salmonella typhimurium vaccine expressing circumsporozoite protein protects against malaria. Science 1988, 240, 336-338

37 Yang, D.M., Fairweather, N., Button, L.L., McMaster, W.R. Kahl, L.P. and Liew, F.Y. Oral Salmonella typhimurium (AroA-) vaccine expressing a major Leishmanial surface protein (gp63) preferentially induces $T$ helper 1 cells and protective immunity against Leishmaniasis. J. Immunot. 1990, 145, 2281-2285

38 Flynn, J.L., Weiss, W.R., Norris, K.A., Seifert, H.S., Kumar, S and So, M. Generation of a cytotoxic T-lymphocyte response using a Salmonella antigen-delivery system. Mol. Microbiol. $1990,4,2111-2118$

39 Gao, X.M., Tite, J.P., Lipscombe, M., Rowland-Jones, S. Ferguson, D.J.P. and McMichael, A.J. Recomhinant Salmonella typhimurium strains that invade nonphagocytic cells are resistant to recognition by antigen-specific cytotoxic T lymphocytes. Infect. Immun. 1992, 60, 3780-3789

40 Turner, S.J., Carbone, F.R. and Strugnell, R.A. Salmonella typhimurium delta aroA delta aroD mutants expressing a foreign recombinant protein induce specific major histocompatibility complex class 1-restricted cytotoxic $\mathrm{T}$ lymphocytes in mice. Infect. Immun. 1993, 61, 5374-5380

41 Pfeifer, J.D., Wick, M.J., Robents, R.L., Finulay, K., Normark, S.J. and Harding, C.V. Phagocytic processing of bacterial antigens for class I MHC presentation to T cells. Nature 1993, $361,359-362$

42 Yan, Z.X., Reuss, F. and Meyer, T.F. Construction of an invertible DNA segment for improved antigen expression by a hybrid Salmonella vaccine strain. Res. Microbiol. 1990, 141, 10031004

43 Yan, Z.X. 1992. Ph.D. thesis. Max Planck Institute, Tübingen.

44 Tijhaar, E.J., Yan, Z.X., Karlas, J.A., Meyer, T.F., Stukart, M.J., Osternaus, A.D.M.E. and Mooi, F.R. Construction and evaluation of an expression vector allowing the stable expression of foreign antigens in a Salmonella typhimurium vaccine strain. Vaccine, 1994, 12, 1004-1011

45 Tijhaar, E.J., Karlas, J.A. Yan, ZX., Meyor, T.F., Osterhaus, A.D.M.E. and Mooi, F.R. Induction of enhanced immune responses by an expression system that allows continuous production of toxic antigens in a Salmonella typhimurium vaccine strains. Submitted for publication.

46 Hoiseth, S.K. and Stocker, B.A.D. Aromatic-dependent Salmonella typhimurium are non-virulent and effective as live vaccines. Nature 1981, 291, 238-239

47 Bullas, L.R. and Ryu, J.I. Salmonella typhimurium LT2 strains which are $r-m+$ for all three chromosomally located systems of DNA restriction and modification. J. Bacteriol. 1983, 156, 471474

48 Sanderson and Stocker, p. 1220-1228, in " $E$. coli and $S$ typhimurium, Cellular and Molecular Biology", Neidhardt et al., edit. 1987. Amer. Soc. Microbiol., Washington, D. C.

49 Studier, F.W., Rosenberg, A.H. Dunn, J.J. and Dubendorff, J.W. Use of T7 RNA polymerase to direct expression of cloned genes. Methods Enzymol. 1990, 189, 60-89

50 Studier, F.W. and Moffatt, B.A. Use of T7 RNA polymerase to direct selective high-level expression of cloned genes. J. Mol. Biol. 1986, 189, 113-130

51 Sambrook, J., Fritsch, E.F. and Maniatis, T. Molecular cloning. A Laboratory Manual, 2nd ed., Cold Spring Harbour Laboratory Press, Cold Spring Harbor, N. Y., 1989

52 Rimmelzwaan, G.F., Siebelink, K.H.J., Broos, H., Drost, G.A., Weijer, K., van Herwijnen, R. and Osterhaus, A.D.M.E. Gag and Env specific serum antibodies in cats after natural and experimental infection with feline immunodeficiency virus. Vet Microbiol. 1994, 39, 153-165 
53 Tokuyasu, K.T. Application of cryoultramicrotomy to immunocytochemistry. J. Microscopy, 1986, 143, 139-149

54 Siebelink, K.H.J., Chu, I., Rimmelzwaan, G.F., Weijer, K., Osterhaus, A.D.M.E. and Bosch, M.L. Isolation and partial characterization of infectious molecular clones of feline immunodeficiency virus obtained directly from bone marrow DNA of a naturally infected cat. J. Virol. 1992, 66, 1091-1097

55 Siebelink, C.H.J., Windrich, R.W., Chu, I., Groen, J., Weijer, K., UytdeHaag, F.G.C.M. and Osterhaus, A.D.M.E. An enzymelinked immunosorbent assay (ELISA) for the detection of feline immunodeficiency virus (FIV) antigen in cell culture and FIV specific antibodies in feline serum. Dev. Biol. Stand. 1990, 72, 189-196
56 Manen, D., Goebel, T. and Caro, L. The par region of pSC101 affects plasmid copy number as well as stability. Mol. Microbiol. $1990,4,1839-1846$

57 Siebelink, K.H.J., Tijhaar, E., Huisman, R.C., Huisman, W., De Ronde, A., Darby, I.H., Francis, M.J., Rimmelzwaan, G.F. and Osterhaus, A.D.M.E. Enhancement of feline immunodeficiency virus infectivity after immunization with envelope glycoprotein subunit vaccines. J. Virol. 1995, 69, 3704-3711

58 Flynn, J.N., Beatty, J.A., Cannon, C.A., Stephens, E.B., Hosie, M.J., Neil, J.C. and Jarret, O. Involvement of gag- and envspecific cytotoxic $T$ lymphocytes in protective immunity to feline immunodeficiency virus. AIDS Res. Hum. Retroviruses 1995, $11,1107-1113$ 